\title{
Black tea is not significantly different from water in the maintenance of normal hydration in human subjects: results from a randomised controlled trial
}

\author{
Carrie H. Ruxton ${ }^{1 *}$ and Valerie A. Hart ${ }^{2}$ \\ ${ }^{1}$ Nutrition Communications, Front Lebanon, Cupar KY15 4EA, UK \\ ${ }^{2}$ Reading Scientific Services Limited, Reading Science Centre, Pepper Lane, Reading RG6 6LA, UK \\ (Received 24 September 2010 - Revised 19 January 2011 - Accepted 20 January 2011 - First published online 30 March 2011)
}

\section{Abstract}

There is a belief that caffeinated drinks, such as tea, may adversely affect hydration. This was investigated in a randomised controlled trial. Healthy resting males ( $n$ 21) were recruited from the general population. Following $24 \mathrm{~h}$ of abstention from caffeine, alcohol and vigorous physical activity, including a $10 \mathrm{~h}$ overnight fast, all men underwent four separate test days in a counter-balanced order with a $5 \mathrm{~d}$ washout in between. The test beverages, provided at regular intervals, were $4 \times 240 \mathrm{ml}$ black (i.e. regular) tea and $6 \times 240 \mathrm{ml}$ black tea, providing 168 or $252 \mathrm{mg}$ of caffeine. The controls were identical amounts of boiled water. The tea was prepared in a standardised way from tea bags and included $20 \mathrm{ml}$ of semi-skimmed milk. All food taken during the $12 \mathrm{~h}$ intervention period was controlled, and subjects remained at rest. No other beverages were offered. Blood was sampled at $0,1,2,4,8$ and $12 \mathrm{~h}$, and a $24 \mathrm{~h}$ urine sample was collected. Outcome variables were whole blood cell count, $\mathrm{Na}, \mathrm{K}$, bicarbonate, total protein, urea, creatinine and osmolality for blood; and total volume, colour, Na, K, creatinine and osmolality for urine. Although data for all twenty-one participants were included in the analysis (mean age 36 years and mean BMI $25 \cdot 8 \mathrm{~kg} / \mathrm{m}^{2}$ ), nineteen men completed all conditions. Statistical analysis, using a factorial ANOVA approach within PROC MIXED, revealed no significant differences between tea and water for any of the mean blood or urine measurements. It was concluded that black tea, in the amounts studied, offered similar hydrating properties to water.

Key words: Tea: Hydration: Caffeine

It is often claimed in the media that caffeinated drinks, such as tea, can adversely affect normal hydration. Messages to drink a glass of water alongside caffeinated beverages to allow for possible diuretic effects have even featured in public health advice $^{(1,2)}$. Caffeine (1,3,7-trimethylxanthine) is a methylxanthine compound found naturally in coffee, tea, chocolate and cola. It can be added to supplements, energy drinks and some medicines ${ }^{(3)}$. Caffeine is rapidly absorbed from the gastrointestinal tract, with plasma levels peaking at $60-90$ min post-ingestion. It is mainly metabolised in the liver by the $\mathrm{P} 450$ enzyme system, producing a range of metabolites including dimethylxanthine, monomethylxanthine and uric $\operatorname{acid}^{(4)}$. The average half-life of caffeine is $2.5-4.5 \mathrm{~h}$ but can vary from 1 to $10 \mathrm{~h}$ in certain individuals ${ }^{(4)}$.

Acute studies on caffeine pills ${ }^{(5,6)}$ have reported modest diuretic effects at caffeine intakes of $5.6-8.75 \mathrm{mg} / \mathrm{kg}$ body weight (i.e. $370-612 \mathrm{mg} / \mathrm{d}$ for an average $70 \mathrm{~kg}$ person). Others $^{(7)}$ have found no significant effects on body mass or blood and urine indicators of hydration at intakes of $3-6 \mathrm{mg} / \mathrm{kg}$ body weight for $5 \mathrm{~d}$ (i.e. $210-420 \mathrm{mg} / \mathrm{d}$ for an average $70 \mathrm{~kg}$ person). However, research on caffeine pills does not relate directly to tea consumption for two reasons. First, tea is a complex substance containing flavonoids, theanine and phenolic acids, as well as methylxanthines, i.e. caffeine, theobromine, theophylline, xanthine, hypoxanthine and guanine ${ }^{(8)}$. Apart from caffeine, the other methylxanthines are present in prepared tea in very small quantities ${ }^{(8)}$ but may have diuretic effects ${ }^{(9)}$. Second, tea as consumed in the UK provides far less caffeine than is typically used in studies of caffeine pills. The National Diet and Nutrition Survey revealed that $77 \%$ of adults are regular tea consumers with a mean daily intake of $540 \mathrm{ml}$ or $2 \cdot 3$ servings $^{(10)}$. Assuming that a cup of tea contains $50 \mathrm{mg}$ of caffeine, as estimated by the Food Standard Agency ${ }^{(11)}$, this equates to a mean daily caffeine intake of $115 \mathrm{mg}$.

Few studies have examined the impact of caffeinated drinks on normal hydration, but all have reported no adverse effects on hydration. Grandjean et al. ${ }^{(12)}$ compared $24 \mathrm{~h}$ consumption of water, cola and coffee in a randomised, controlled, cross-over trial ( $n 18$ sedentary adults). Results 
showed no significant differences between the drinks in terms of the participants' mean body weight, urine volume, specific gravity, creatinine and osmolality. Neither were there any significant differences in serum measurements of electrolytes, haematocrit, osmolality, creatinine, urea or protein. The average caffeine intake over $24 \mathrm{~h}$ ranged from 114 to $253 \mathrm{mg}$ (or from 1.4 to $3.13 \mathrm{mg} / \mathrm{kg}$ body weight). Fiala et $a{ }^{(13)}$ tested ad libitum caffeinated $v$. non-caffeinated cola over $3 \mathrm{~d}$ ( $n$ 10) using a randomised cross-over design. During the trial, participants were physically active for $4 \mathrm{~h} / \mathrm{d}$. Apart from a significant difference in urine colour, there were no differences in urine or blood measurements of hydration. The average daily caffeine intake in the caffeinated condition was $245 \mathrm{mg}$. The findings from these trials are similar to those reported by the lower-dose caffeine pill studies.

Only one study has examined the influence of tea on hydration $^{(14)}$, but this was undertaken at altitude. Participants ( $n$ 13) were members of an expedition at Mount Everest Base Camp and consumed either ad libitum tea or water for $24 \mathrm{~h}$. Urine samples were measured in order to assess fluid balance, but these revealed no significant differences in specific gravity, electrolyte balance $\left(\mathrm{K}^{+}\right.$and $\mathrm{Na}^{+}$) or urine colour between the tea and water conditions. However, that study did not follow a controlled randomised design, and the influence of altitude makes it difficult to translate the findings to the general population.

Therefore, data are lacking on how tea, as consumed, has an impact on the hydration of sedentary human subjects. The aim of the present trial was to assess the impact of four or six servings of black (i.e. regular) tea on blood and urine measurements of hydration $v$. a water control.

\section{Methods}

The present study was conducted according to the guidelines laid down in the Declaration of Helsinki, and all procedures involving human subjects were approved by the Reading Independent Ethics Committee. Written informed consent was obtained from all subjects.

\section{Experimental design}

The study was a single-centre, randomised, controlled, crossover trial to assess body hydration following consumption of black tea against a water control in healthy sedentary male volunteers. Tea intake was studied at two levels: four or six servings (as mugs). These levels were selected as they exceeded average tea intakes in the UK and would enable a thorough test of the model. Studies on caffeine pills usually provide a fixed amount of caffeine/kg body weight. However, as the present study was intended to be naturalistic, identical amounts of tea were given to all subjects regardless of body weight. The intervention was carried out during a $12 \mathrm{~h}$ controlled session for each beverage tested. Subjects and investigators were not blinded due to the obvious differences between the test and control beverages.

\section{Subjects}

Following the screening of thirty-three volunteers recruited from the Reading Scientific Services Limited (Reading, Berks, UK) volunteer panel by word of mouth or by public advertisement (January-March 2010), twenty-one healthy adult males were accepted into the study. Exclusion criteria were females, smokers, systemic medication likely to interfere with outcome variables, significant chronic illness, allergy or intolerance to tea or milk, excessive caffeine consumption ( $>$ ten cups of coffee/d or equivalent), BMI $<20$ or $>30 \mathrm{~kg} / \mathrm{m}^{2}$ and concurrent participation in other food or clinical trials. Females were excluded due to a risk that the menstrual cycle may have an impact on fluid balance. The target sample size of twenty was selected based on previous hydration trials and was determined sufficient to detect any clinically relevant differences in hydration. A power calculation could not be made since the only published data on tea and hydration were collected at altitude as part of an uncontrolled trial ${ }^{(14)}$.

\section{Beverages provided}

In the present study, black tea was chosen as the test beverage because it is the most popular type consumed in Western countries $^{(15)}$. Although black and green teas originate from the same plant, Camellia sinensis, the caffeine content of black tea leaves is slightly higher than that of green tea leaves $\left(41.5-67.4 v .32 .5 \mathrm{mg} / \mathrm{g}^{(16)}\right)$. It was decided to add milk because this is a common way of preparing tea in the $\mathrm{UK}^{(10)}$, although no sugar was added as $63 \%$ of UK consumers drink tea unsweetened ${ }^{(10)}$.

Round tea bags, sourced from a nationally representative retailer, were prepared in a standardised way as follows: add tea bag to mug, add $230 \mathrm{ml}$ freshly boiled water to the mug and stir the tea bag three times clockwise. Leave to brew for $40 \mathrm{~s}$, stir further three times, squeeze the tea bag gently against the side of the mug and remove. Add $20 \mathrm{ml}$ semi-skimmed milk. The total volume was $240 \mathrm{ml}$, which allowed for a $10 \mathrm{ml}$ loss due to the removal of the tea bag and the addition of milk. The drinks were presented immediately after preparation. Boiled water, in identical amounts, was presented as the control beverage. This was allowed to cool slightly before consumption. Water was selected as the control, because it is viewed as an optimal fluid for hydration ${ }^{(1,2)}$.

The caffeine content of the tea beverage, as prepared by the standardised method, was measured using HPLC. This was found to be $16 \cdot 7-21 \cdot 1 \mathrm{mg} / 100 \mathrm{ml}$ with an average of $18.9 \mathrm{mg} / 100 \mathrm{ml}$, giving an estimate of $42 \mathrm{mg}$ for the caffeine content of one mug of tea (i.e. $220 \mathrm{ml}$ of tea without addition of milk). This means that the four-mug protocol provided $168 \mathrm{mg}$ of caffeine, while the six-mug protocol provided $252 \mathrm{mg}$ of caffeine.

\section{Intervention in detail}

Fig. 1 gives an overview of the intervention. Participants were randomly assigned to complete four study days in counterbalanced order. Of the four study days, two were for the 


\begin{tabular}{|c|c|c|c|c|c|c|c|c|c|c|c|c|c|c|c|}
\hline \multicolumn{2}{|c|}{$\begin{array}{l}\text { Preparation } \\
\text { (1 d) }\end{array}$} & \multicolumn{13}{|c|}{ Study day (h) } & \multirow[t]{2}{*}{$\begin{array}{l}\text { Washout } \\
\qquad(5 \mathrm{~d})\end{array}$} \\
\hline $14 \mathrm{~h}$ & $10 \mathrm{~h}$ & 0 & 1 & 2 & 3 & 4 & 5 & 6 & 7 & 8 & 9 & 10 & 11 & 12 & \\
\hline \multirow{4}{*}{$\begin{array}{l}\text { Abstain } \\
\text { from } \\
\text { SPA, } \\
\text { alcohol, } \\
\text { caffeine }\end{array}$} & \multirow{4}{*}{$\begin{array}{l}\text { Abstain } \\
\text { from } \\
\text { SPA and } \\
\text { all food } \\
\text { and } \\
\text { beverages } \\
\text { except } \\
\text { water }\end{array}$} & $4 \mathrm{D} / 6 \mathrm{D}$ & & $4 \mathrm{D} / 6 \mathrm{D}$ & & $6 \mathrm{D}$ & & $4 \mathrm{D} / 6 \mathrm{D}$ & & $6 \mathrm{D}$ & & $4 \mathrm{D} / 6 \mathrm{D}$ & & & \multirow{4}{*}{$\begin{array}{c}\text { No } \\
\text { restrictions }\end{array}$} \\
\hline & & Bloods & Bloods & Bloods & & Bloods & & & & Bloods & & & & Bloods & \\
\hline & & & Food & & & Food & & & & Food & & & & & \\
\hline & & \multicolumn{13}{|c|}{$\begin{array}{l}\text { 24-h urine collection } \\
\text { Standardised diet provided }\end{array}$} & \\
\hline
\end{tabular}

Fig. 1. Overview of the protocol. SPA, strenuous physical activity; 4D, 4-serving protocol drink; 6D, 6-serving protocol drink.

black tea conditions ( 4 or $6 \times 240 \mathrm{ml}$ servings), while two were for the associated water conditions.

After abstaining from vigorous physical activity, alcohol and caffeinated drinks for $14 \mathrm{~h}$ in order to reduce the risk of dehydration before the trial, participants embarked on a $10 \mathrm{~h}$ overnight fast during which time only water was allowed. On entering the laboratory on each study day, baseline blood measurements were taken by a trained venepuncturist. Immediately afterwards, a test or control beverage was provided. Thereafter, beverages were offered at 2, 6 and $10 \mathrm{~h}$ for the four-serving protocol, and at 2, 4, 6, 8 and $10 \mathrm{~h}$ for the six-serving protocol. Subjects remained at rest during their time in the laboratory. Urine was collected for $24 \mathrm{~h}$ from arrival at the laboratory on each study day.

A standardised diet was offered during the $12 \mathrm{~h}$ of laboratory attendance. This consisted of a croissant at breakfast, $400 \mathrm{~g}$ mince and pasta bake at lunch and a round of sandwiches plus a slice of fruitcake at supper. For ethical reasons, participants were allowed to request a sip of water in addition to the test or control beverages. However, only one participant requested an additional sip of water during the four-serving tea condition. On leaving the laboratory, subjects were free to eat and drink without restriction.

After each study day, participants were given a $5 \mathrm{~d}$ washout period, during which time there were no restrictions other than those described in the exclusion criteria.

\section{Blood and urine analyses}

Blood samples were taken by a trained venepuncturist at screening and then on each study day at baseline, 1, 2, 4, 8 and $12 \mathrm{~h}$. At each time point, a $2 \mathrm{ml}$ sample was collected in a tube with EDTA additive for haematology, and a $5 \mathrm{ml}$ sample was collected in a $\mathrm{SST}^{\mathrm{TM}}$ tube with silica clot activator for biochemistry and serum osmolality. These were transported in a chilled state for analysis by The Doctors Laboratory (London, UK). Samples were analysed for the following parameters: whole blood cell count (e.g. haematocrit) using the Sysmex XE 2100 (Sysmex, Inc., Kobe, Japan); electrolytes (K, Na and bicarbonate), total protein, urea and creatinine, all using the Roche/Hitachi Modular ${ }^{\circledR}$ P800 module (Hitachi Limited, Hitachinaka-Ibaraki, Japan); osmolality using the Advanced $^{\circledR}$ Model 3320 Micro-Osmometer (Advanced Instruments, Inc., Norwood, MA, USA).

We collected $24 \mathrm{~h}$ urine samples at screening and then on each study day. Samples were analysed for the following parameters: total volume, electrolyte concentration, creatinine using the Roche/Hitachi Modular ${ }^{\circledR}$ P800 module (Hitachi Limited) and osmolality using the Advanced $^{\circledR}$ Model 3320 Micro-Osmometer (Advanced Instruments, Inc.). A $20 \mathrm{ml}$ aliquot was removed from the $24 \mathrm{~h}$ urine collection for the assessment of $\mathrm{K}, \mathrm{Na}$ and creatinine. A $20 \mathrm{ml}$ sample of mid-stream urine was also taken for the assessment of colour. This was coded as following: 1, colourless; 2, light yellow; 3, yellow; 4, dark yellow. This coding method was not validated.

\section{Statistical analysis}

Data for all twenty-one participants were analysed in an intention-to-treat model. The urine measurements were analysed using a factorial ANOVA approach within PROC MIXED using SAS software (SAS Institute, Inc., Cary, NC, USA). Fixed factors in the model included beverage (tea $v$. water), protocol (four $v$. six mugs) and visit (participants attended the laboratory on four occasions during the intervention period), while the subjects were modelled as a random factor. The interactions 'beverage $x$ protocol', 'beverage $\times$ visit' and 'protocol $\times$ visit' were also considered.

The urine measurements at screening were entered as covariates into the model to allow for the fact that different subjects were likely to have different baseline urine measurements. Blood measurements were analysed using a very similar approach to the urine measurements, with the additional step that data from time points at 1, 2, 4, 8 and $12 \mathrm{~h}$ were modelled using the repeated-measures facility within PROC MIXED. Measurements over each $12 \mathrm{~h}$ experimental period were likely to be mutually correlated with each other, and it was anticipated that an autocorrelation or ante-dependence covariance structure was the most appropriate for the data.

\section{Results}

Although data for all twenty-one participants were included in the analysis, nineteen men completed all conditions. At baseline, mean age was $36(20-54)$ years, mean weight was $81 \cdot 8$ $(66-97) \mathrm{kg}$ and mean BMI was $25 \cdot 8(22-30) \mathrm{kg} / \mathrm{m}^{2}$. Of the nineteen men, seventeen were Caucasian. Using baseline weight and measured caffeine levels in the test beverage, average caffeine intakes in the four-mug protocol were $2.07 \mathrm{mg} / \mathrm{kg}$ body weight (range $1.73-2.55$ ) $\mathrm{mg} / \mathrm{kg}$, and in the six-mug protocol were $3 \cdot 11 \mathrm{mg} / \mathrm{kg}$ body weight (range $2 \cdot 6-3 \cdot 82$ ) $\mathrm{mg} / \mathrm{kg}$. 
Table 1. Blood results for the four- and six-serving protocols*

(Mean values with their standard errors, $n 19$ )

\begin{tabular}{|c|c|c|c|c|c|c|c|}
\hline & \multirow[b]{2}{*}{ Condition } & \multicolumn{6}{|c|}{ Time (h) } \\
\hline & & 0 & 1 & 2 & 4 & 8 & 12 \\
\hline \multirow[t]{12}{*}{ Haematocrit (\%) } & W4 & & & & & & \\
\hline & Mean & $42 \cdot 8$ & 43.0 & 43.3 & $43 \cdot 2$ & $43 \cdot 8$ & $43 \cdot 2$ \\
\hline & SEM & 0.40 & 0.37 & 0.42 & 0.43 & 0.62 & 0.69 \\
\hline & $\mathrm{T} 4$ & & & & & & \\
\hline & Mean & 43.4 & 43.7 & $43 \cdot 7$ & $43 \cdot 6$ & $45 \cdot 0$ & 44.7 \\
\hline & SEM & 0.49 & 0.52 & 0.52 & 0.48 & 0.80 & 0.78 \\
\hline & W6 & & & & & & \\
\hline & Mean & $43 \cdot 6$ & $43 \cdot 6$ & $43 \cdot 6$ & $43 \cdot 8$ & 44.2 & $44 \cdot 3$ \\
\hline & SEM & 0.46 & 0.37 & 0.39 & 0.46 & 0.64 & 0.56 \\
\hline & T6 & & & & & & \\
\hline & Mean & $43 \cdot 3$ & $43 \cdot 2$ & 43.3 & 43.4 & $44 \cdot 4$ & 44 \\
\hline & SEM & 0.51 & 0.43 & 0.42 & 0.45 & 0.68 & 0.87 \\
\hline \multirow{12}{*}{$\mathrm{Na}(\mathrm{mmol} / \mathrm{l})$} & W4 & & & & & & \\
\hline & Mean & 143 & 142 & 143 & 142 & 142 & 144 \\
\hline & SEM & 0.46 & 0.60 & 0.46 & 0.37 & 0.36 & 0.36 \\
\hline & $\mathrm{T} 4$ & & & & & & \\
\hline & Mean & 143 & 142 & 143 & 143 & 142 & 144 \\
\hline & SEM & 0.26 & 0.28 & 0.49 & 0.36 & 0.42 & 0.40 \\
\hline & W6 & & & & & & \\
\hline & Mean & 143 & 142 & 142 & 143 & 141 & 142 \\
\hline & SEM & 0.41 & 0.39 & 0.33 & 0.36 & 0.34 & 0.38 \\
\hline & T6 & & & & & & \\
\hline & Mean & 143 & 142 & 142 & 142 & 142 & 143 \\
\hline & SEM & 0.41 & 0.38 & 0.30 & 0.31 & 0.36 & 0.44 \\
\hline \multirow{12}{*}{$\mathrm{K}(\mathrm{mmol} / \mathrm{l})$} & W4 & & & & & & \\
\hline & Mean & 4.5 & $4 \cdot 6$ & 4.7 & 4.7 & $4 \cdot 6$ & 4.4 \\
\hline & SEM & 0.07 & 0.08 & 0.07 & 0.06 & 0.06 & 0.05 \\
\hline & $\mathrm{T} 4$ & & & & & & \\
\hline & Mean & $4 \cdot 6$ & $4 \cdot 6$ & $4 \cdot 6$ & $4 \cdot 6$ & $4 \cdot 6$ & 4.5 \\
\hline & SEM & 0.08 & 0.07 & 0.07 & 0.08 & 0.08 & 0.06 \\
\hline & W6 & & & & & & \\
\hline & Mean & 4.5 & $4 \cdot 7$ & $4 \cdot 7$ & $4 \cdot 6$ & $4 \cdot 6$ & 4.5 \\
\hline & SEM & 0.08 & 0.09 & 0.08 & 0.07 & 0.08 & 0.08 \\
\hline & T6 & & & & & & \\
\hline & Mean & 4.6 & 4.7 & 4.7 & $4 \cdot 7$ & 4.6 & 4.4 \\
\hline & SEM & 0.09 & 0.08 & 0.07 & 0.08 & 0.07 & 0.06 \\
\hline \multirow[t]{12}{*}{ Bicarbonate $(\mathrm{mmol} / \mathrm{l})$} & W4 & & & & & & \\
\hline & Mean & 23 & 23 & 23 & 24 & 23 & 23 \\
\hline & SEM & 0.60 & 0.33 & 0.43 & 0.36 & 0.68 & 0.31 \\
\hline & $\mathrm{T} 4$ & & & & & & \\
\hline & Mean & 23 & 23 & 23 & 23 & 24 & 23 \\
\hline & SEM & 0.44 & 0.44 & 0.46 & 0.40 & 0.40 & 0.42 \\
\hline & W6 & & & & & & \\
\hline & Mean & 22 & 23 & 23 & 23 & 23 & 22 \\
\hline & SEM & 0.58 & 0.32 & 0.49 & 0.49 & 0.51 & 0.53 \\
\hline & T6 & & & & & & \\
\hline & Mean & 22 & 22 & 23 & 23 & 23 & 23 \\
\hline & SEM & 0.53 & 0.45 & 0.60 & 0.51 & 0.42 & 0.45 \\
\hline \multirow{12}{*}{ BUN (mmol/l) } & W4 & & & & & & \\
\hline & Mean & $5 \cdot 4$ & $5 \cdot 1$ & $5 \cdot 1$ & 4.9 & 5.9 & $6 \cdot 3$ \\
\hline & SEM & 0.17 & 0.15 & 0.14 & 0.15 & 0.47 & $0 \cdot 16$ \\
\hline & T4 & & & & & & \\
\hline & Mean & $5 \cdot 3$ & $5 \cdot 2$ & $5 \cdot 2$ & 4.9 & 5.9 & $6 \cdot 3$ \\
\hline & SEM & 0.27 & 0.21 & 0.22 & 0.21 & 0.20 & 0.23 \\
\hline & W6 & & & & & & \\
\hline & Mean & $5 \cdot 6$ & $5 \cdot 3$ & 5.5 & $5 \cdot 1$ & $5 \cdot 7$ & 6 \\
\hline & SEM & 0.28 & 0.26 & 0.31 & 0.31 & 0.21 & 0.25 \\
\hline & T6 & & & & & & \\
\hline & Mean & 5.5 & $5 \cdot 3$ & $5 \cdot 20$ & $5 \cdot 1$ & 5.9 & 5.9 \\
\hline & SEM & 0.32 & 0.32 & 0.32 & 0.24 & 0.23 & 0.23 \\
\hline \multirow[t]{6}{*}{ Creatinine $(\mathrm{mmol} / \mathrm{l})$} & W4 & & & & & & \\
\hline & Mean & 88 & 85 & 84 & 82 & 88 & 88 \\
\hline & SEM & 1.97 & $2 \cdot 22$ & $2 \cdot 23$ & $2 \cdot 15$ & 2.48 & 2.90 \\
\hline & $\mathrm{T} 4$ & & & & & & \\
\hline & Mean & 90 & 87 & 85 & 84 & 89 & 90 \\
\hline & SEM & 2.52 & $2 \cdot 58$ & 2.62 & $2 \cdot 27$ & $2 \cdot 37$ & 3.36 \\
\hline
\end{tabular}


Table 1. Continued

\begin{tabular}{|c|c|c|c|c|c|c|c|}
\hline & \multirow[b]{2}{*}{ Condition } & \multicolumn{6}{|c|}{ Time (h) } \\
\hline & & 0 & 1 & 2 & 4 & 8 & 12 \\
\hline & W6 & & & & & & \\
\hline & Mean & 90 & 86 & 85 & 83 & 85 & 88 \\
\hline & SEM & 2.44 & 2.55 & 2.44 & $2 \cdot 27$ & 2.49 & $3 \cdot 16$ \\
\hline & T6 & & & & & & \\
\hline & Mean & 89 & 86 & 83 & 82 & 87 & 89 \\
\hline & SEM & $2 \cdot 76$ & $2 \cdot 31$ & $2 \cdot 38$ & 2.45 & 2.59 & $2 \cdot 91$ \\
\hline \multirow[t]{12}{*}{ Total protein (g/l) } & W4 & & & & & & \\
\hline & Mean & 70 & 71 & 72 & 72 & 72 & 72 \\
\hline & SEM & 0.70 & 0.70 & 0.67 & 0.65 & 0.76 & 0.68 \\
\hline & $\mathrm{T} 4$ & & & & & & \\
\hline & Mean & 71 & 72 & 72 & 74 & 72 & 73 \\
\hline & SEM & 0.71 & 0.70 & 0.64 & 0.83 & 0.85 & 0.85 \\
\hline & W6 & & & & & & \\
\hline & Mean & 72 & 72 & 73 & 74 & 73 & 73 \\
\hline & SEM & 1.04 & 0.78 & 0.82 & $1 \cdot 13$ & 0.78 & 0.85 \\
\hline & T6 & & & & & & \\
\hline & Mean & 72 & 71 & 72 & 74 & 73 & 73 \\
\hline & SEM & 0.96 & 0.61 & 0.64 & 0.77 & 0.94 & $0 \cdot 80$ \\
\hline \multirow[t]{12}{*}{ Osmolality (mOsmol/kg) } & W4 & & & & & & \\
\hline & Mean & 290 & 289 & 291 & 288 & 291 & 291 \\
\hline & SEM & $1 \cdot 15$ & 1.66 & 2.42 & 1.04 & 1.51 & 1.17 \\
\hline & $\mathrm{T} 4$ & & & & & & \\
\hline & Mean & 290 & 289 & 291 & 287 & 292 & 294 \\
\hline & SEM & 1.08 & 0.96 & 1.89 & 1.59 & 1.56 & 1.55 \\
\hline & W6 & & & & & & \\
\hline & Mean & 290 & 288 & 290 & 289 & 289 & 290 \\
\hline & SEM & 1.41 & 1.66 & 1.48 & $1 \cdot 81$ & $1 \cdot 38$ & $2 \cdot 24$ \\
\hline & T6 & & & & & & \\
\hline & Mean & 290 & 290 & 288 & 289 & 289 & 288 \\
\hline & SEM & 1.82 & 1.63 & 1.54 & $1 \cdot 36$ & $2 \cdot 20$ & 3.23 \\
\hline
\end{tabular}

Baseline blood results revealed that all measurements were within normal ranges, indicating that the subjects were not dehydrated at the start of the study day. The statistical analysis of the blood parameters indicated no significant differences in body hydration after consuming water or tea beverages for either the four- or six-serving protocol. None of the interactions, i.e. 'beverage $\times$ protocol', 'beverage $\times$ visit' and 'protocol $\times$ visit', was statistically significant. Blood results for the six-mug protocol are shown in Table 1 . The urine results indicated that there were no significant differences in body hydration after consuming water or tea beverages for either the four- or the six-serving protocol. The only significant finding was that urine colour was associated with the visit $(F=6.21 ; P<0.05)$, in that urine colour was darker on visits 3 and 4 compared with visits 1 and 2 . This suggests that participants may have consumed less fluid outwith the intervention period on those dates. Or the finding could be spurious since the translation of urine colour into numerical values relies on human judgement. Again, none of the interactions mentioned earlier was statistically significant. Table 2 presents the $24 \mathrm{~h}$ urine results for both the four- and sixmug protocols and the screening results for comparison.

Further analysis was carried out to assess how body weight influenced urine output by plotting $24 \mathrm{~h}$ urine output against body weight for each protocol and calculating Pearson's correlation coefficients. In both the water and tea conditions, urine output was slightly higher in the lighter subjects compared with the heavier subjects. The association between body weight and urine output reached statistical significance only for the six-mug tea protocol $(r-0.56 ; P=0.005)$. However, when the outlier (who was also the lightest subject at $66 \mathrm{~kg}$ ) was omitted, the association became non-significant ( $r$ 0.39; $P=0.094$ ).

There were eleven adverse events reported by eleven subjects: three subjects reported bruising or haematoma associated with blood sampling; six subjects reported headaches; one reported cold; one reported nausea. It was determined by the study medic that none of the adverse events was related to the test or control beverages.

\section{Discussion}

Caffeine is believed to have an adverse effect on hydration because it increases blood flow to the kidneys and inhibits the re-absorption of $\mathrm{Na}, \mathrm{Ca}$ and $\mathrm{Mg}$, thus stimulating urine output $^{(17)}$. There is observational evidence that caffeine provokes the need to urinate by stimulating the bladder's detrusor muscles ${ }^{(18)}$, although this was not confirmed by a randomised controlled trial in women with detrusor overactivity ${ }^{(19)}$. However, much of the evidence underpinning the diuretic theory 
Table 2. Urine results for the four- and six-serving protocols*

(Mean values with their standard errors, $n$ 19)

\begin{tabular}{|c|c|c|c|c|c|c|c|c|c|c|}
\hline & \multicolumn{2}{|c|}{ Screening } & \multicolumn{2}{|c|}{ W4 } & \multicolumn{2}{|c|}{$\mathrm{T} 4$} & \multicolumn{2}{|c|}{ W6 } & \multicolumn{2}{|c|}{ T6 } \\
\hline & Mean & SEM & Mean & SEM & Mean & SEM & Mean & SEM & Mean & SEM \\
\hline Urine volume (ml) & 1385 & 90 & 1228 & 110 & 1117 & 90 & 1458 & 130 & 1498 & 140 \\
\hline Creatinine $(\mathrm{mmol} / 24 \mathrm{~h})$ & $17 \cdot 3$ & $2 \cdot 74$ & $15 \cdot 0$ & 1.68 & $14 \cdot 1$ & 1.01 & 14.4 & $1 \cdot 27$ & $13 \cdot 0$ & 1.07 \\
\hline $\mathrm{Na}(\mathrm{mmol} / 24 \mathrm{~h})$ & $107 \cdot 7$ & $14 \cdot 8$ & $107 \cdot 5$ & $12 \cdot 4$ & $106 \cdot 1$ & $8 \cdot 6$ & $104 \cdot 7$ & $14 \cdot 1$ & 124.9 & $10 \cdot 7$ \\
\hline $\mathrm{K}(\mathrm{mmol} / 24 \mathrm{~h})$ & 83 & $15 \cdot 7$ & $66 \cdot 0$ & $6 \cdot 8$ & $61 \cdot 0$ & $5 \cdot 1$ & $65 \cdot 3$ & $6 \cdot 1$ & 70.9 & $8 \cdot 6$ \\
\hline Osmolality (mOsmol/kg) & 640 & $65 \cdot 7$ & 664 & $48 \cdot 0$ & 726 & $45 \cdot 5$ & 637 & 63.4 & 581 & $47 \cdot 3$ \\
\hline Colour & 2 & 0.2 & 3 & 0.1 & 3 & 0.2 & 3 & 0.1 & 3 & 0.1 \\
\hline
\end{tabular}

W4, water four-serving protocol; T4, tea four-serving protocol; W6, water six-serving protocol; T6, tea six-serving protocol.

${ }^{*}$ Mean values were not significantly different for all results between W4 and T4, and between W6 and T6 $(P>0.05)$.

has arisen from animal studies or human interventions, which have used caffeine pills and/or high caffeine intakes.

In the present study, there were no significant differences in mean blood and urine measurements of hydration between the tea and water conditions, nor were there any significant differences in mean $24 \mathrm{~h}$ urine output, indicating that concerns about excessive urination following the consumption of tea may be misplaced for most individuals. However, an additional analysis did find an association between body weight and $24 \mathrm{~h}$ urine output when six mugs of tea were consumed. This became non-significant when the outlier, the lightest person in the group, was removed from the analysis. It is also worth noting that the urine results showed a nonsignificant trend towards a higher mean $24 \mathrm{~h} \mathrm{Na}$ level in the six-mug tea condition, which was due to higher Na levels in three of the lighter subjects. Therefore, it would be worth repeating this trial in a group of lighter subjects, e.g. women or adolescents, to investigate how tea consumption may influence hydration status. It is worth noting that no association between body weight and urine output was observed for the four-mug protocol, an amount which exceeds average daily tea consumption in the UK (i.e. $2 \cdot 3$ servings) ${ }^{(10)}$.

In a review of the evidence, Ruxton ${ }^{(3)}$ described eight randomised controlled trials, which had assessed hydration following caffeine consumption. In five of these, daily caffeine intakes of $1.4-6 \mathrm{mg} / \mathrm{kg}$ body weight $(98-420 \mathrm{mg} / \mathrm{d}$ for an average $70 \mathrm{~kg}$ person) did not adversely affect normal hydration $^{(7,12,13,20,21)}$. A notable example is the $5 \mathrm{~d}$ trial by Armstrong et al. ${ }^{(7)}$ during which subjects consumed $3-6 \mathrm{mg} / \mathrm{kg}$ body weight as caffeine pills. The three remaining trials reported significantly increased urination following caffeine consumption $^{(5,6,22)}$, although in two of these, caffeine intakes were high at $8.75 \mathrm{mg} / \mathrm{kg}$ body weight or $642 \mathrm{mg} / \mathrm{d}$. In addition, two trials outwith the review found no evidence of altered hydration following caffeine consumption combined with intense exercise. In the study by Millard-Stafford et $a l^{(23)}$, a beverage providing $195 \mathrm{mg}$ caffeine/l was tested under warm, humid conditions, while Del Coso et al. ${ }^{(24)}$ provided $6 \mathrm{mg} / \mathrm{kg}$ body weight of caffeine as pills during $120 \mathrm{~min}$ of cycling in the heat.

These studies, using a wide range of caffeine intakes and often physically active subjects under warm conditions, represent a thorough test of the impact of caffeine on normal hydration. However, they do not entirely reflect the likely impact of tea, which is a more complex substance. Nevertheless, the findings suggest that lower amounts of caffeine, as would be found in an average person's intake of caffeinated beverages $^{(10)}$, are tolerated by the body and do not cause dehydration. This concurs with an earlier review by Maughan \& Griffin ${ }^{(9)}$, which concluded that the caffeine levels found in commonly consumed beverages probably have no diuretic action, although the authors have highlighted a lack of specific data on tea. The present trial, which provided 168 or $252 \mathrm{mg}$ of caffeine as tea, addresses this gap and confirms Maughan \& Griffin's conclusions ${ }^{(9)}$.

As with most trials, there were limitations, which should be noted. The main one was the lack of control of beverages consumed at the end of the laboratory period, which may have influenced the urine results, although not the blood results. Another limitation was the lack of information about room temperature in the laboratory, which, nevertheless, would have had a minimal impact on hydration. It would have been useful to measure blood over $24 \mathrm{~h}$ to give a better assessment of hydration, but this was not possible within funding and time constraints. Habituation to caffeine is thought to be an important factor ${ }^{(25)}$, thus regular caffeine consumers may have responded differently to non-consumers of caffeine in terms of hydration and urine output. The methodology was designed to minimise any such impact by excluding high consumers of caffeine ( $>$ ten cups of coffee/d or equivalent) and instructing participants to avoid caffeinated drinks for $24 \mathrm{~h}$ before each study day. Given the average half-life of caffeine is $2.5-4.5 \mathrm{~h}^{(4)}$, it is likely that all participants had excreted any previous caffeine before beginning the trial. It would have also been interesting to estimate habitual caffeine and $\mathrm{Na}$ intakes before the trial. Na consumption can influence blood and urine $\mathrm{Na}$ measurements, although we attempted to minimise variation in the present trial by providing identical meals during the $12 \mathrm{~h}$ intervention period and ensuring that subjects were fasted for $10 \mathrm{~h}$ before entering the laboratory. While the caffeine content of the tea provided in the trial was measured, levels of other methylxanthines that could have an impact on hydration were not, although these would not have varied in the test beverage due to the standardised preparation of the tea.

Tea is consumed by the majority of the UK adult population, particularly elderly people $\mathrm{e}^{(10)}$, thus health professional advice and media comment, which incorrectly identify tea as 
a diuretic, could be misleading and serve to drive consumption towards less healthy beverages. Tea is a rich source of flavonoids, which have been associated with a reduced risk of heart disease and stroke in epidemiological studies at intakes of about four cups/ $\mathrm{d}^{(26,27)}$. In addition, experimental research has reported that exposure to tea flavonoids reduces LDL-cholesterol oxidation $^{(28,29)}$ and improves flow-mediated dilatation $^{(30)}$. Thus, tea could be considered a healthy choice of beverage.

Given the findings of the present trial that consumption of tea at either four or six servings/d had no adverse effects on hydration, it could be argued that public health advice relating to caffeinated drinks should be revised. Both the Food Standards Agency ${ }^{(2)}$ and the Royal College of Nursing ${ }^{(1)}$ currently suggest that tea and coffee can act as diuretics and infer that water should be drunk alongside caffeinated beverages to offset the potential for fluid losses. However, the average intake of tea in the UK is $540 \mathrm{ml} / \mathrm{d}^{(10)}$, which is far below the $1320 \mathrm{ml}$ offered in the six-serving protocol of the present study. Thus, it is highly unlikely that most tea consumers would experience excessive diuresis. Indeed, the present trial indicates that the hydrating properties of water and tea are similar.

\section{Conclusions}

Tea and water offered similar hydrating properties at intakes of four to six servings/d, equating to 168 or $252 \mathrm{mg}$ caffeine. Given that average intakes of tea in the UK are considerably lower than the levels tested in the present study, the risk of dehydration in response to regular tea consumption is minimal. Public health advice should be updated to reflect the true contribution of tea to fluid requirements.

\section{Acknowledgements}

Funding for the study was provided by the Tea Advisory Panel. The Tea Advisory Panel is supported by an unrestricted educational grant from the UK Tea Council, the trade association for the UK tea industry. The content reflects the opinion of the authors. The contribution of each author was as follows: C. H. R. co-designed the trial and wrote the manuscript; V. A. $\mathrm{H}$. co-designed the trial, directed the statistical analysis and contributed to the Methods section of the paper.

\section{References}

1. Royal College of Nursing/National Patient Safety Agency (2007) Water for Health: Hydration Best Practice Toolkit for Hospitals and Healthcare. London: Royal College of Nursing/National Patient Safety Agency. www.rcn.org.uk/ newsevents/campaigns/nutritionnow/tools_and_resources/ hydration (accessed 19 July 2010).

2. Food Standards Agency (2010) Drinks. London: Food Standards Agency. www.eatwell.gov.uk/asksam/healthydiet/ drinksq/ (accessed 19 July 2010).

3. Ruxton CHS (2008) The impact of caffeine on mood, cognitive function, performance and hydration: a review of benefits and risks. Nutr Bull 33, 15-25.
4. Australian New Zealand Food Authority (2000) Report of the Expert Working Group on the Safety Aspects of Dietary Caffeine. Canberra/Wellington: ANZFA.

5. Wemple RD, Lamb DR \& McKeever KH (1997) Caffeine vs. caffeine-free sports drinks: effects on urine production at rest and during prolonged exercise. Int J Sports Med 18, 40-46.

6. Bird ET, Parker BD, Kim HS, et al. (2005) Caffeine ingestion and lower urinary tract symptoms in healthy volunteers. Neurourol Urodyn 24, 611-615.

7. Armstrong LE, Pumerantz AC, Roti MW, et al. (2005) Fluid, electrolyte, and renal indices of hydration during 11 days of controlled caffeine consumption. Int J Sport Nutr Exerc Metab 15, 252-265.

8. Chen ZM, Wang HF, You XQ, et al. (2002) The chemistry of tea non-volatiles. In Tea: Bioactivity and Therapeutic Potential [Y Zhen, editor]. London: Taylor \& Francis.

9. Maughan RJ \& Griffin J (2003) Caffeine ingestion and fluid balance: a review. J Hum Nutr Diet 16, 411-420.

10. Henderson L, Gregory J \& Swan G (2002) National Diet and Nutrition Survey: Adults Aged 19 to 64 Years. London: FSA.

11. Food Standards Agency (2004) Survey of Caffeine Levels in Hot Beverages. London: FSA Surveillance Unit.

12. Grandjean AC, Reimers KJ, Bannick KE, et al. (2000) The effect of caffeinated, non-caffeinated, caloric and non-caloric beverages on hydration. J Am Coll Nutr 19, 591-600.

13. Fiala KA, Casa DJ \& Roti MW (2004) Rehydration with a caffeinated beverage during the nonexercise periods of 3 consecutive days of 2-a-day practices. Int J Sport Nutr Exerc Metab 14, 419-429.

14. Scott D, Rycroft JA, Aspen J, et al. (2004) The effect of drinking tea at high altitude on hydration status and mood. Eur J Appl Physiol 91, 493-498.

15. International Tea Committee (2009) Annual Bulletin of Statistics 2009. London: International Tea Committee. www. inttea.com (accessed 19 July 2010)

16. Cabrera C, Giménez R \& López MC (2003) Determination of tea components with antioxidant activity. J Agric Food Chem 51, 4427-4435.

17. Birkner E, Grucka-Mamczar E, Zwirska-Korczala K, et al. (2006) Influence of sodium fluoride and caffeine on the kidney function and free-radical processes in that organ in adult rats. Biol Trace Elem Res 109, 35-48.

18. Arya LA, Myers DL \& Jackson ND (2000) Dietary caffeine intake and the risk for detrusor instability: a case-control study. Obstet Gynecol 96, 85-89.

19. Swithinbank L, Hashim H \& Abrams P (2005) The effect of fluid intake on urinary symptoms in women. J Urol 174, 187-189.

20. Falk B, Burstein R, Rosenblum J, et al. (1990) Effects of caffeine ingestion on body fluid balance and thermoregulation during exercise. Can J Physiol Pharmacol 68, 889-892.

21. Roti MW, Casa DJ, Pumerantz AC, et al. (2006) Thermoregulatory responses to exercise in the heat: chronic caffeine intake has no effect. Aviat Space Environ Med 77, 124-129.

22. Neuhauser-Berthold, Beine S, Verwied SC, et al. (1997) Coffee consumption and total body water homeostasis as measured by fluid balance and bioelectrical impedance analysis. Ann Nutr Metab 41, 29-36.

23. Millard-Stafford ML, Cureton KJ, Wingo JE, et al. (2007) Hydration during exercise in warm, humid conditions: effect of a caffeinated sports drink. Int J Sport Nutr Exerc Metab 17, 163-177.

24. Del Coso J, Estevez E \& Mora-Rodriguez R (2009) Caffeine during exercise in the heat: thermoregulation and fluidelectrolyte balance. Med Sci Sport Exerc 41, 164-173. 
25. Smit HJ \& Rogers PJ (2000) Effects of low doses of caffeine on cognitive performance, mood and thirst in low and higher caffeine consumers. Psychopharmacology (Berl) 152, 167-173.

26. Peters U, Poole C \& Arab L (2001) Does tea affect cardiovascular disease? A meta-analysis. Am J Epidemiol 154, 495-503.

27. Hooper L, Kroon PA, Rimm EB, et al. (2008) Flavonoids, flavonoid-rich foods, and cardiovascular risk: a meta-analysis of randomized controlled trials. Am J Clin Nutr 88, 38-50.
28. Kris-Etherton PM \& Keen CL (2002) Evidence that the antioxidant flavonoids in tea and cocoa are beneficial for cardiovascular health. Curr Opin Lipid 13, 41-49.

29. Stangl V, Lorenz M \& Stangl K (2006) The role of tea and tea flavonoids in cardiovascular health. Mol Nutr Food Res 50, 218-228.

30. Jochmann N, Lorenz M, Krosigk A, et al. (2008) The efficacy of black tea in ameliorating endothelial function is equivalent to that of green tea. BrJ Nutr 99, 863-868. 